Invited critical review

\title{
Natriuretic peptides and NGAL in heart failure: Does a link exist?
}

\author{
Alberto Palazzuoli*, Matteo Beltrami, Marco Pellegrini, Ranuccio Nuti \\ Department of Internal Medicine, UOS Cardiology, S. Maria alle Scotte Hospital Siena, University of Siena, Italy
}

\section{A R T I C L E I N F O}

\section{Article history:}

Received 28 April 2012

Received in revised form 10 July 2012

Accepted 10 July 2012

Available online 20 July 2012

\section{Keywords:}

B-type natriuretic peptide

NT pro-BNP

Heart failure

NGAL

\begin{abstract}
A B S T R A C T
In recent years there has been growing interest in the development of new diagnostic tools and particularly in laboratory tests for the identification of heart failure (HF) patients. Because of the rise in HF occurrence, it is necessary to use simple and reliable method to recognize those patients at risk before the onset of the clinical symptoms. To date HF diagnosis remains difficult: its symptoms and signs are often non specific as well as being poor sensitive indicators for HF severity. Throughout the last 10 years published literature has highlighted a boom in the use of biomarkers for HF. Both B-type and N-terminal pro-B-type natriuretic peptides have demonstrated specific role in heart failure diagnosis, as well as risk assessment. A single determination of BNP at any time during the development of chronic heart failure (CHF) provides a clinically useful tool to establish the outcome. Renal dysfunction is often associated with heart failure and predicts adverse clinical outcomes. Many studies have recently suggested the clinical use of serum neutrophil gelatinase-associated lipocalin (NGAL) levels in patients admitted to the hospital for acute HF can be used to estimate the risk of early worsening renal function. This could be potentially applied in clinical practice for early identification of renal dysfunction development in patients with HF. NGAL levels appear also to predict renal dysfunction in patients with chronic HF and preserved renal function. For all these reasons, BNP and NGAL are two emerging tools useful for diagnosis and prognosis in HF. The combination of two laboratory biomarkers could potentially identify patients with more elevated risks of both cardiac hemodynamic impairment and kidney dysfunction.
\end{abstract}

(c) 2012 Elsevier B.V. All rights reserved.

\section{Contents}

1. Introduction ... . . . . . . . . . . . . . . . . . . . . . . . . . . . . . . . . 1832

2. Natriuretic peptides in heart failure . . . . . . . . . . . . . . . . . . . . . . . . . . . . . . . . . . . . . 1833

3. Natriuretic peptides and imaging . . . . . . . . . . . . . . . . . . . . . . . . . . . . . . . . . . 1835

4. NGAL in heart failure . . . . . . . . . . . . . . . . . . . . . . . . . . . . . . . . . . . . . . . 1836

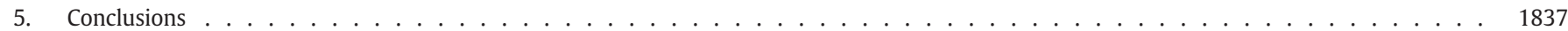

References . . . . . . . . . . . . . . . . . . . . . . . . . . . . . . . . . . . . . . . . 1837

\section{Introduction}

Heart failure has a significant impact on the health care system, and its occurrence is ever increasing in the elderly. It is generally estimated that HF currently affects $0.4 \%-2 \%$ of the European population [1]. In United States approximately 5,8 million patients were affected by HF [2]. It is well known that the incidence of HF rises substantially

\footnotetext{
* Corresponding author at: Department of Internal Medicine and Metabolic Diseases, Cardiology Section, Le Scotte Hospital, Viale Bracci, 53100 Siena, Italy. Tel.: + 39 577585363, + 39 577585461; fax: + 39577233480.

E-mail address: palazzuoli2@unisi.it (A. Palazzuoli).
}

with age. The prevalence of HF in people over 65 years of age has been reported to be $6 \%-10 \%$. This data shows that heart failure is a chronic disease that affects a large part of health care resources [3]. Before 1990 , as many as 60 to $70 \%$ of patients died within 5 years of the diagnosis of systolic heart failure, and hospitalization as a consequence of the exacerbation of symptoms was frequent. Moreover in recent years neither there has been no observed improvement, neither in outcome nor in rehospitalization [4].

The great variability that characterizes HF syndrome depends on the heterogeneity in patient population and multiple etiologies [5]. There are big differences between patients in terms of cardiac or non cardiac morbidity and genetic characteristics. This is the primary consideration approaching patients with HF, because the pathophysiological process varies between cases [6]. Many clinical trials in acute 
heart failure syndrome (AHFS) have given poor results because an incorrect classification of the patients enrolled. The natural history and treatment strategies are often the same, however clinical approach and strategy should be specifically addressed [7]. Early diagnosis is very important for therapy optimization and to improve the outcomes. The ability to recognize cardiac insufficiency at an early stage before signs and symptoms manifest, depends on the specificity, sensibility and accuracy of the tools used. For this reason, there is an increasing interest in the development of new biomarkers and a great number of laboratory tests have recently been put forward for early LV process remodeling identification.

Each biomarker needs to reach its diagnostic and prognostic accuracy. Morrow and de Lemos have defined three major criteria a biomarker should fulfill to be clinically useful: 1 - accurate, repeated measurements must be available at a reasonable cost and with short turnaround times; 2 - the biomarker must provide information that is not already available from a careful clinical assessment; 3 knowing the measured level should aid in medical decision making [8]. One of the biggest hopes for utilizing biomarker testing is to determine the level of disease severity as a means to triage medical decisions as well as to monitor their responses. Moreover each biomarker should include some preconditions: some characteristics are linked to chemical detection (in vivo and in vitro stability, low cost, sensitivity, international standardization reference tested for gender and age), some others need to respond to clinical practice (good diagnostic and prognostic accuracy, useful in therapy management, and favorable cost-effectiveness ratio) [9] (Fig. 1). In clinical practice it is hard to find specific biomarkers containing all these characteristics, although several classes of biomarkers are currently accepted in the field of heart failure [10]. An approach with multiple biomarkers could help to classify patients with high risk of clinical worsening and in need of hospitalization and intensive care. BNP and NGAL are two emerging tools useful for diagnosis and prognosis in HF. Hereunder we describe their clinical use and their field of application on the basis of past and recent literature.

\section{Natriuretic peptides in heart failure}

The most important biomarker for heart failure are brain natriuretic peptide (BNP) and its precursor NT proBNP. B-type natriuretic peptide is a member of a class of hormones that regulate blood pressure. BNP and its amino-terminal cleavage equivalent $\mathrm{N}$-terminal prohormone brain natriuretic peptide (NT-proBNP) originate from a pre-proBNP hormone of 134 residues that is cleaved to yield a 108 amino acid intracellular pro-hormone, proBNP108; from proBNP108, BNP and NT-proBNP are released in varying amounts. BNP is synthesized in the heart as a reaction to cardiac wall distension, and stretching and

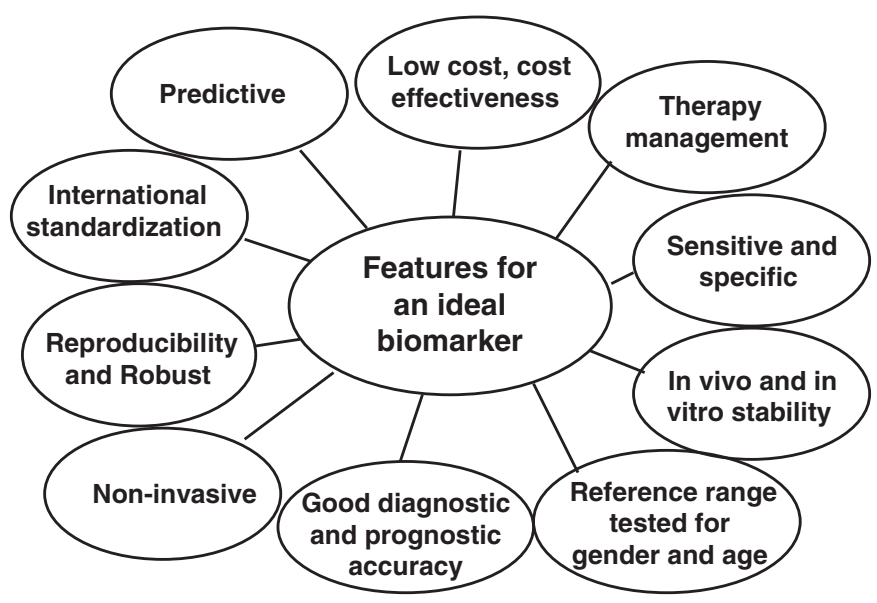

Fig. 1. Clinical and biochemical features for an ideal biomarker. neurohormonal activation. BNP leads to natriuresis and vasodilatation activation with associated inhibition of the renin angiotensin system and adrenergic activity. BNP plays an important regulatory role in response to acute increases in ventricular volume by opposing the vasoconstriction, sodium retention, and antidiuretic effects of the activated renin-angiotensin-aldosterone system.

Several studies demonstrated that increased levels of circulating BNP are found in early stages of HF. The level of BNP in the blood continues to increase as the HF disease advances. Reports have indicated that there is a relationship between the severity of the clinical signs and symptoms of HF and BNP concentrations. BNP is also useful in screening asymptomatic patients at risk of developing HF (elderly patients with diabetes, hypertension or asymptomatic coronary artery disease). Blood BNP concentrations represent an independent assessment of ventricular function and could be employed as a biomarker for preclinical ventricular dysfunction [11].

Recently natriuretic peptide (NP) measurement has been included in the HF diagnosis algorithm (Table 1). A BNP level below $100 \mathrm{pg} / \mathrm{ml}$ exclude HF diagnosis; values of BNP between 100 and $400 \mathrm{pg} / \mathrm{ml}$, require imaging techniques to confirm heart failure diagnosis. On the contrary BNP values above $400 \mathrm{pg} / \mathrm{ml}$ are associated with high accuracy and a worsening outcome. Values of BNP between 100 and $400 \mathrm{pg} / \mathrm{ml}$ represent a grey zone where it is not possible to ascertain their diagnostic role accurately and to predict a value for this biomarker [12]. In patients in the emergency department (ED) for acute dyspnea the measurement of BNP levels can distinguish cardiac from pulmonary causes: patients with heart failure have higher peptide levels, as opposed to patients with dyspnea caused by respiratory diseases $[13,14]$. The REDHOT study on patients admitted in ED with shortness of breath, clarify the role of BNP values in the diagnosis of heart failure and in the prediction of the future outcome [15]. Recently NT pro BNP has been studied in the emergency department to establish the severity of both disease and outcome, confirming that its measurement is associated with good classification of patient care [16]. Introduction of NT-proBNP testing for heart failure in the ED setting reduces the time of discharge. NT pro BNP is strongly linked to subsequent utilization of hospital resources [17].

A recent report investigated the applicability of urinary B-type natriuretic peptide levels in the diagnosis of heart failure compared to plasma BNP levels. In the detection of HF, the measurement of urinary BNP offers similar results, besides having the advantage of being a noninvasive test (Table 2) [18].

BNP measurement is also validated by hemodynamic studies. BNP accurately reflects ventricular filling pressure, pulmonary pressure and is correlated inversely with cardiac output [19]. Iwanaga et al. observe that plasma BNP levels reflect left ventricular end-diastolic wall stress (EDWS) more than they do left ventricular end-diastolic

Table 1

American Heart Association recommendation (2005 and 2009) for the use of natriuretic peptides in HF diagnosis and risk prediction.

2009 focused update: ACCF/AHA

Guidelines for the diagnosis and management of heart failure in adults

Class IIa

2005 guideline recommendations

Measurement of BNP can be useful in the evaluation of patients presenting in the ur-

gent care setting in whom the clinical diagnosis of $\mathrm{HF}$ is uncertain.

(Level of evidence: $A$ )

2009 focused update recommendations

Measurement of natriuretic peptides (BNP and NT-proBNP) can be useful in the evaluation of patients presenting in the urgent care setting in whom the clinical diagnosis of HF is uncertain. Measurement of natriuretic peptides (BNP and NT-proBNP) can be useful in risk stratification.

(Level of evidence: $A$ )

Comments

Modified recommendation (added a caveat on natriuretic peptides and their role as part of total evaluation, in both diastolic and systolic dysfunctions). 
Table 2

BNP and NTpro-BNP clinical trials with associated cut off in acute heart failure diagnosis.

\begin{tabular}{|c|c|c|c|c|}
\hline Author & Year & Study design & Cut-off BNP or NT-pro BNP & Findings \\
\hline $\begin{array}{l}\text { Morrison, } \\
\text { LK } \\
{[14]}\end{array}$ & 2002 & $\begin{array}{l}\text { Evaluate how a rapid assay for BNP levels could } \\
\text { help physicians to differentiate cardiac from } \\
\text { pulmonary causes of dyspnea in ED. }\end{array}$ & $\begin{array}{l}\text { A BNP value of } 94 \mathrm{pg} / \mathrm{ml} \text { had a sensitivity of } \\
86 \% \text {, specificity of } 98 \% \text { and an accuracy of } 91 \% \\
\text { for differentiating CHF from pulmonary disease. }\end{array}$ & $\begin{array}{l}\text { Patients with CHF had BNP levels significantly } \\
\text { higher than the group of patients with a final } \\
\text { diagnosis of pulmonary disease. Rapid testing } \\
\text { of BNP in the ED should help differentiate } \\
\text { pulmonary from cardiac etiologies of dyspnea. }\end{array}$ \\
\hline $\begin{array}{l}\text { Maisel, A } \\
\text { [15] }\end{array}$ & 2004 & $\begin{array}{l}\text { Examine the relationships among BNP levels } \\
\text { within the diagnostic range, perceived congestive } \\
\text { heart failure severity, clinical decision making, } \\
\text { and outcomes of the CHF patients presenting to } \\
\text { emergency department (ED). }\end{array}$ & $\begin{array}{l}\text { Entrance criteria included a BNP level }>100 \mathrm{pg} / \mathrm{ml} \text {. } \\
\text { Admitted patients were divided into two groups } \\
\text { based on BNP levels above and below } 200 \mathrm{pg} / \mathrm{ml} \\
\text { to study differences in outcome rates. }\end{array}$ & $\begin{array}{l}\text { The BNP levels can predict future outcomes and } \\
\text { thus may aid physicians in making triage decisions } \\
\text { about whether to admit or discharge patients. } \\
\text { Emerging clinical data will help further refine } \\
\text { biomarker-guided outpatient therapeutic and } \\
\text { monitoring strategies involving BNP. }\end{array}$ \\
\hline $\begin{array}{l}\text { Mueller, C } \\
\text { [13] }\end{array}$ & 2004 & $\begin{array}{l}\text { Prospective, randomized, controlled study } \\
\text { presenting to the ED with acute dyspnea: assigned } \\
\text { to a diagnostic strategy involving the measurement } \\
\text { of BNP, compared to the standard method. } \\
\text { Discharge time and total cost of treatment were the } \\
\text { primary end points. }\end{array}$ & $\begin{array}{l}\text { 1) BNP level of } 100 \mathrm{pg} / \mathrm{ml} \text { to separate dyspnea } \\
\text { caused by HF from other causes of dyspnea. 2) BNP } \\
\text { level below } 100 \mathrm{pg} / \mathrm{ml} \text { the diagnosis of HF was } \\
\text { considered unlikely. 3) BNP peptide level of more } \\
\text { than } 500 \mathrm{pg} / \mathrm{ml}, \mathrm{HF} \text { was considered the most likely } \\
\text { diagnosis. 4) BNP levels between } 100 \text { and } 500 \mathrm{pg} / \mathrm{ml} \text {, } \\
\text { the protocol recommended the use of clinical } \\
\text { judgment and possible further diagnostic test. }\end{array}$ & $\begin{array}{l}\text { Used in conjunction with other clinical information, } \\
\text { rapid measurement of BNP in the emergency } \\
\text { department improved the evaluation and treatment } \\
\text { of patients with acute dyspnea and thereby reduced } \\
\text { the time of discharge and the total cost of treatment. }\end{array}$ \\
\hline $\begin{array}{l}\text { Rutten, JH } \\
\text { [17] }\end{array}$ & 2008 & $\begin{array}{l}477 \text { patients presenting dyspnea were randomized } \\
\text { for either rapid measurement or no measurement } \\
\text { of NT-proBNP. Time to discharge and costs related } \\
\text { to hospital admission were primary end points. } \\
\text { Bootstrap analysis was used for comparison of costs } \\
\text { and 30-day mortality between the NT-proBNP and } \\
\text { control group. }\end{array}$ & $\begin{array}{l}\text { For ruling out HF, cutoff values of } 93 \mathrm{pg} / \mathrm{mL} \text { in male } \\
\text { and } 144 \mathrm{pg} / \mathrm{mL} \text { in female patients were used. For } \\
\text { ruling in } \mathrm{HF} \text {, a cutoff value of } 1017 \mathrm{pg} / \mathrm{mL} \text { was used. }\end{array}$ & $\begin{array}{l}\text { Introduction of NT-proBNP testing for heart failure } \\
\text { in the ED setting reduces the time to discharge and } \\
\text { is associated with a cost reduction trend. }\end{array}$ \\
\hline $\begin{array}{c}\text { Song, J } \\
{[18]}\end{array}$ & 2011 & $\begin{array}{l}\text { Urinary and plasma BNP levels were measured on } \\
160 \text { patients with HF classifiable into NYHA stages } \\
\text { I, II, III, or IV and } 30 \text { healthy control subjects. The } \\
\text { heart function of each patient was examined by } \\
\text { echocardiography. }\end{array}$ & $\begin{array}{l}\text { The optimal cutoff value for urinary BNP was } \\
36.5 \mathrm{pg} / \mathrm{ml} \text {. }\end{array}$ & $\begin{array}{l}\text { Urinary and plasma BNP levels among patients in } \\
\text { the HF group were significantly higher than those } \\
\text { in the control group. Urinary BNP levels were } \\
\text { correlated with plasma BNP levels and NYHA grades } \\
\text { of HF and were negatively correlated with LVEF. }\end{array}$ \\
\hline $\begin{array}{l}\text { Luchner, A } \\
\text { [16] }\end{array}$ & 2012 & $\begin{array}{l}\text { Prospective randomized, multicentre trial } \\
\text { conducted in patients }>65 \text { years old. NT-proBNP } \\
\text { as a marker of heart failure and other cardiac } \\
\text { diseases was assessed. Primary endpoint was } \\
\text { hospital admission; secondary endpoints were } \\
\text { intermediate/intensive care unit (IMC/ICU) } \\
\text { admission, length of stay, re-hospitalization } \\
\text { and death, or re-hospitalization. }\end{array}$ & $\begin{array}{l}\text { Was considered three different groups of patients } \\
\text { with NT-proBNP }<150 \mathrm{pg} / \mathrm{mL} \text { (low), with NT-proBNP } \\
\text { between } 150 \text { and } 1800 \mathrm{pg} / \mathrm{mL} \text { (intermediate), with } \\
\text { NT-proBNP }>1800 \mathrm{pg} / \mathrm{mL} \text { (high). }\end{array}$ & $\begin{array}{l}\text { Knowledge of NT-proBNP had no significant effect } \\
\text { on the primary endpoint hospital admission and } \\
\text { the secondary endpoints. However patients with } \\
\text { high open NT-proBNP ( }>1800 \mathrm{pg} / \mathrm{mL} \text { ) were more } \\
\text { likely to be admitted to the hospital and IMC/ICU } \\
\text { whereas patients with low open NT-proBNP } \\
\text { ( }<150 \mathrm{pg} / \mathrm{mL} \text { ) were less likely to be admitted } \\
\text { compared with patients with blinded NT-proBNP. }\end{array}$ \\
\hline
\end{tabular}

pressure (EDP), not only in patients with systolic HF, but also in patients with diastolic HF. The relationship of left ventricular EDWS to plasma BNP may provide a better fundamental understanding of the interindividual heterogeneity in BNP levels and their clinical utility in diagnosis and management [20].

BNP is also a useful follow up test and to assess prognosis of patients with HF. Elevated plasma BNP levels upon admission are a valid independent predictor of in-hospital mortality in acute decompensated HF with preserved or reduced systolic function, which don't depend on other clinical or laboratory variables [21]. Serial measurements of BNP in the chronic outpatient setting appear to convey additional prognostic value to relevant adverse outcomes, including death or destabilization of CHF requiring hospitalization, and they are thus recommended in clinical practice. Several studies that used natriuretic peptides pre-discharge indicate that BNP levels appear to be the strongest predictors for identifying subsequent death or hospital admission within 6 months [22,23]. The dosage of BNP provides more prognostic information than other necrosis biomarkers as well as imaging indexes like ejection fraction and shortening fraction. In the Australia-New Zealand Heart Failure Group Trial patients with chronic HF and reduced systolic function levels of NT pro BNP above the average were linked to an increased risk of new decompensated HF events, which all caused mortality within 18 months of the follow up [24]. In the Valsartan Heart Failure (Val-Heft) trial, which included 5010 patients with mild to moderate chronic HF receiving recommended medical therapy; an increment of $500 \mathrm{ng} / \mathrm{L}$ above the baseline concentration of NT pro BNP carried an increase in adjusted risk of 3.8\% for mortality and 3.0\% for hospitalization for HF [25].
Although NP have been useful in HF diagnosis and risk prediction, some confusing factors could influence the levels of NP. Age, race, obesity, and renal dysfunction may complicate the clinical interpretation of circulating BNP levels in patients with chronic and stable congestive heart failure. Obesity may reduce diagnostic accuracy of B-type natriuretic peptide; the BNP levels were lower in obese patients hospitalized for HF compared to non obese patients [26]. In obese patients, the determination of BNP levels reduced time on onset of the appropriate treatment. Obese patients showed half the short and the long term mortality of non obese patients [27]. Also body mass index influences the selection of cut-points for BNP in diagnosing acute HF and in order to preserve sensitivity it is necessary to place a lower cut-off in severely obese patients [28]. This way it's possible to maintain high standard in the prediction of serious symptoms, impaired haemodynamics, and higher mortality at all levels of BMI. Redfield et al. confirm the impact of age and sex on BNP observed in subjects without cardiovascular disease, therefore NP measurement would be used to take into account discriminatory values adjusted for sex and age [29]. It has been demonstrated that age increases the level of circulating BNP; this is related to the decline in myocardial function, myocardial fibrosis with diastolic dysfunction and the reduction in clearance of natriuretic peptides typical of senescence. Race is another factor that could influence plasma BNP levels; for each NYHA class perception, Hispanic and black races have a higher level compared to the Caucasian population [30].

Beside physiologic factors, several inflammatory and systemic diseases can also affect NP values. Many studies demonstrated the impact of renal insufficiency on natriuretic peptides independently from cardiac 
function being dependent not only on renal insufficiency severity but also on the duration of the disease [31]. Cruz et al. calculated that in the presence of this associated condition, BNP levels increased of $1 / 3$ compared to a patient with normal renal function [32]. Anemia is another condition frequently associated with more advanced HF stages and its correction could reduce natriuretic peptide levels [33]. Another limitation in clinical practice concerns the time of measurement that reflects volume status: NP is released by increased volume load and wall stretch, and is influenced by systemic idro-saline retention. After treatment with drugs of proven efficacy, there is a progressive reduction of BNP, considered to be evaluation of congestion. Finally several cardiac factors, even in the absence of increased filling pressure and straight forward HF, can cause NP alteration: increased LV mass, reduced right ventricular function, mitral valve disease, high pulmonary pressure for primitive or secondary respiratory disease, pulmonary embolism and atrial fibrillation are all causes of potential NP increase. NP measurement has high sensitivity but low specificity and laboratory tests need to be confirmed by a clinical and traditional diagnostic screening process.

\section{Natriuretic peptides and imaging}

After traditional first line evaluations (ECG, thorax radiography and clinical examination), echocardiography is the technique recommended for patients affected by heart failure, thanks to its easy availability and reproducibility. Echocardiography still remains an important tool for the diagnosis of left ventricular (LV) dysfunction; many authors suggest a complementary approach for echocardiography and BNP in patients with HF symptoms. This way of proceeding improves diagnostics and the classification of patients [34]. Contrariwise Maisel et al. suggest that the use of BNP assay reduces the need for echocardiography in many patients with left ventricular dysfunction [35]. Moreover, for patients hospitalized after HF diagnosis, for the prediction of future cardiac death or rehospitalization for CHF, BNP assay in pre-discharge is more effective than doppler echocardiographic examination [36].

BNP and NT-proBNP levels correlate positively with left ventricular dimension volumes and mass in a variety of populations. However, there is only a mild correlation between BNP and systolic parameters such as left ventricular ejection fraction (LVEF) and stroke volume [37]. In a meta-analysis, Latour-Perez et al. showed that NP had a wide range of correlation ranging from high to low values. This range could be linked to different population characteristics and to the severity of systolic dysfunction. BNP and NT proBNP have particularly positive predictive values when it comes to more severe systolic ventricular dysfunction. BNP is linked to indexes of filling pressure, including transmitral early filling velocity (E) and early diastolic annular velocity TDI $E \mid E^{\prime}$. However, a single value for BNP and NT pro-BNP is unable to provide a reliable estimation of filling pressure across individuals, although very low levels retain strong negative predictive values for elevated filling pressure. BNP is correlated with restrictive diastolic pattern and pulmonary hypertension with right systolic dysfunction. NP levels are also higher in patients with left ventricular hypertrophy. The diagnosis or exclusion of suspected heart failure, both systolic or diastolic, can be performed accurately by echocardiographic measurement of LV longitudinal systolic function [38]. Moreover, BNP is strongly linked with ventricular longitudinal systolic function. BNP and NT pro-BNP also reflect left atrial size, correlating positively with left atrial volume. However this relation appears diminished in patients with decompensated HF and in subjects with advanced systolic HF.

High levels of BNP and NT pro BNP are correlated with the level of diastolic dysfunction. Most patients with HF have both systolic and diastolic LV dysfunctions, but in some cases the syndrome can occur with isolated systolic or diastolic dysfunction. Heart failure with preserved left ventricular ejection fraction (LVEF) involves almost $50 \%$ of patients with HF [39]. In clinical practices it is not easy to distinguish HF with preserved LVEF from heart failure with reduced EF on the basis of traditional diagnostic tools. HF with preserved LVEF is characterized by a non-dilated, usually hypertrophied left ventricle in which LVEF is preserved at rest. The parameters of LV relaxation and filling pressure are markedly unbalanced. Invasive measurement is the standard reference for establishing LV end diastolic filling pressure and pulmonary pressure. In this setting Doppler and tissue Doppler study are the most reliable and accurate methods. Although diastolic dysfunction and consequent filling pressure alteration can be recognized by this examination, there is a grey zone in which it is not possible to identify patients with elevated filling pressure. The diagnosis in these patients is facilitated by NP measurement $[40,41]$. Lubien et al. successfully demonstrated this with BNP level over $200 \mathrm{pg} / \mathrm{ml}$ and not clear eco Doppler study [42]. The two-step approach of eco Doppler and NP measurement is able to recognize community patients with increasing risk of developing diastolic impairment and HF syndrome development [43].

Bistola et al. have found a prognostic value in the evaluation of right ventricular tissue Doppler imaging (RV TDI) combined with increased plasma BNP. They enrolled patients with advanced heart failure secondary to ischemic or idiopatic dilated cardiomiopathy. RV TDI and high levels of BNP predict adverse cardiac outcomes in advanced CHF [44]. As a consequence of this quality, some authors have suggested the use of echocardiographic multi-parameter score (EMPS) based on systolic and diastolic function, left ventricular chamber remodeling, valvular lesions, pulmonary arterial pressure, and regional wall-motion abnormalities in combination with NP measurement, to better detect LV global function and the severity of heart failure [34].

Findings resulting from a comparison between BNP and LV remodelling evaluated by cardiac magnetic resonance (CMR) confirmed that the hormone is related to microvascular obstruction (MO), left ventricular function, myocardial perfusion, myocardial scar and infarct size. Bruder et al. have found a strong correlation between the extent of delayed enhancement (DE), microvascular obstruction in contrast-enhanced MRI and the plasma level of NT-pro-BNP in patients with acute myocardial infarction. The association of biomarker and delayed enhancement highlights the strong prognostic impact of contrast-enhanced CMR after acute myocardial infarction. This data is useful for the evaluation of patients who could develop HF and ventricular enlargement [45]. The prognostic value of $\mathrm{N}$-terminal pro-brain natriuretic peptide with CMR imaging parameters of cardiac function and infarct size was assessed in patients with ST-segment elevation myocardial infarction. Compared to CK-MB, troponin T, CRP, and creatinine clearance, NT-pro-BNP level $>260 \mathrm{pg} / \mathrm{ml}$ is a strong independent predictor of left ventricular ejection fraction in patients with non anterior wall myocardial infarction. NT-pro-BNP could be useful in early risk stratification of these patients [46]. Mayr et al. confirmed the correlation between NT-pro BNP and acute and chronic infarct size, EF and systolic wall tension after MI assessed by CMR [47]. Furthermore NT-proBNP levels strongly correlate with left ventricular wall stress and sphericity index [48].

BNP levels were observed in patients who underwent ECG-gated SPECT and echocardiography to assess systolic and diastolic function. This study evaluated left ventricular functional parameters calculated using quantitative electrocardiography (ECG)-gated myocardial perfusion single photon emission computed tomography (QGS). In addition to LV systolic parameters, diastolic parameters were compared with those by ultrasound echocardiography (UCG) and also with plasma B-type natriuretic peptide (BNP) concentrations. LV systolic and diastolic dysfunctions evaluated by QGS are strongly correlated with that by UCG or BNP. The QGS functional parameters give new additional information in patients at risk of developing cardiac failure [49].

BNP was compared with PET scanning in patients with chronic heart failure and ischemic cardiomyopathy. Ischemia, hibernation, and myocardial scarring were evaluated and it was found that a decrease in BNP value was associated with extensive myocardial scarring [50]. 


\section{NGAL in heart failure}

neuthrophil gelatinase associated lipocalin (NGAL) is a member of the lipocalin superfamily of proteins. These are typically small proteins characterised by their ability to bind small, hydrophobic molecules in a structurally conserved pocket, and to form macromolecular complexes. Human NGAL is a protein which can be covalently bound to gelatinase from neutrophils through a single intermolecular disulfide bridge polypeptide chain of 178 amino-acid residues with a calculated molecular mass of $22 \mathrm{kDa}$, but glycosylation increases its apparent molecular mass to $25 \mathrm{kDa}$. NGAL has many synonyms: it is also known as neutrophil lipocalin (NL or HNL for the human form), lipocalin 2, oncogene protein, $24 \mathrm{p} 33$ or uterocalin in the mouse, and neu-related lipocalin. In neutrophils and urine it occurs as a monomer, with a small percentage of dimer and trimer, and it also occurs as a complex with 92-kDa human neutrophil type IV collagenase, also called gelatinase B or matrix metalloproteinase-9 (MMP-9). In physiological conditions NGAL is detected at very low levels in several human tissues, including kidney, heart, stomach, lungs and colon. However, the expression of NGAL becomes markedly induced in the post ischemic kidney and it has been suggested that NGAL may play a role in repair and nephrogenesis [32]. Measured from baseline NGAL levels rise rapidly in both urine and blood after renal injury. It can be measured in blood as a point of care test, and in the urine using a standardized laboratory platform. NGAL is a novel biomarker of Human Kidney Injury (AKI) and heart failure.

NGAL is elevated in association with Human Kidney Injury (patients with AKI or who later develop AKI) in patients presenting to the emergency department. The potential utility of NGAL levels in providing early information regarding the risk of AKI development would be clinically important, and could be used in a variety of clinical situations including intensive care, emergency medicine, and renal transplantation [51]. Growing evidence suggests that NGAL may also be involved in cell survival, inflammation, and matrix degradation. It seems to be upregulated in "stressed" cells, especially in cardiomiocytes, in which case the correlation with HF is important. Recently some studies showed an increased serum NGAL in patient with acute and chronic HF.

In a study by Aghel A. et al, in 91 patients admitted to the hospital with acute HF, the ones who developed worsening renal function
(WRF) had significantly higher median admission serum NGAL levels compared to those without WRF. They observed that patients with admission NGAL values of $\geq 140 \mathrm{ng} / \mathrm{ml}$ had a 7.4 -fold chance of developing WRF [52]. NGAL is not only a risk predictor for renal injury but an overall strong risk marker for cardiac events. The GALLANT prospective trial shows that plasma NGAL is a good prognostic biomarker of poor outcome at early stages in patients with acute heart failure adding new information respect to BNP measurement (Fig. 2). Similar results were found by Alvelos et al. in a 3 month follow up period [53]. An elevated serum NGAL concentration could predict a worse short term prognosis in patients with acute HF and meanwhile suggest renal damage in these patients. Furthermore, the ability to predict is independent from other variables also associated with the outcome, indexes of baseline renal function. This suggests the potential and complementary role of NGAL respect to BNP alone in identifying patients at more increased risk. While BNP is a marker of neuro-hormonal activation as well as ventricular dysfunction and overload, NGAL is a marker of kidney injury and in particular of renal tubular damage. The combined measurement of blood BNP and NGAL levels seems to increase the prognostic accuracy in patients with heart failure; NGAL might have better predictive ability compared to BNP, as it is impaired earlier and more frequently in cases of poor prognosis. We can measure the levels of two biomarkers at the time of discharge: high levels of NGAL could be important for early and more frequent follow-up as well as for therapy which safely uses diuretics [54] (Table 3).

There is an interesting relationship between serum NGAL levels and estimated glomerular filtration rates in the setting of acute HF. Poniatowski et al. have recognized serum and urine NGAL as sensitive early markers of renal dysfunction in patients with chronic HF and normal serum creatinine but reduced eGFR [55]. The prognostic impact of reduced glomerular filtration rate (GFR) in chronic heart failure (CHF) is known; the reduction of glomerular filtration and increased urinary albumin excretion (UAE) determine the outcome in patients with chronic heart failure (HF). However renal impairment in CHF patients is not only characterised by decreased eGFR and increased UAE, but also by the presence of tubular damage as measured by increased urinary NGAL concentrations. In detail the extension of tubular damage is related to the increased urinary concentrations of three urinary a

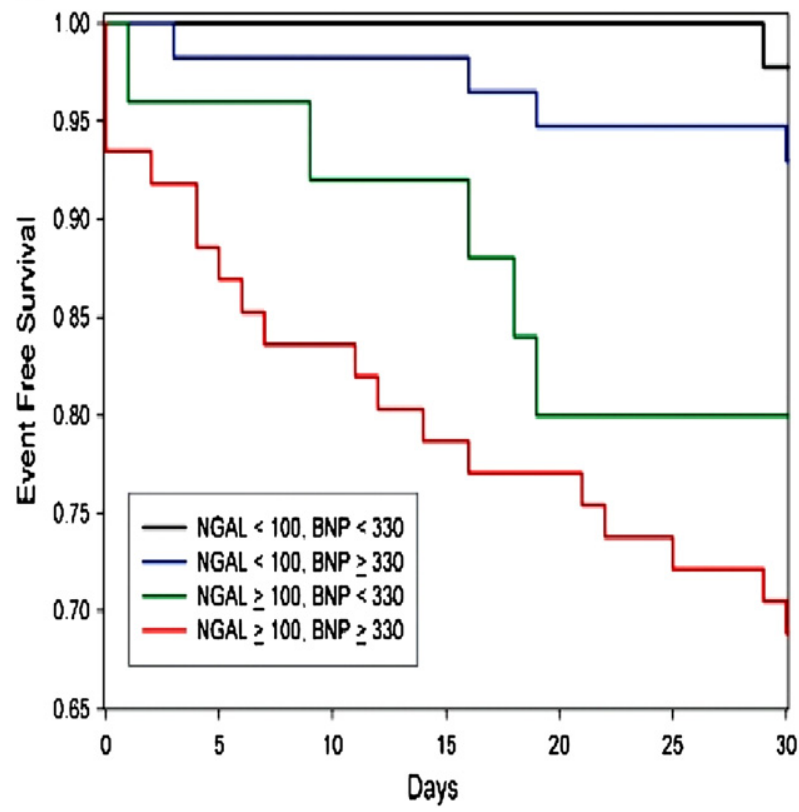

b

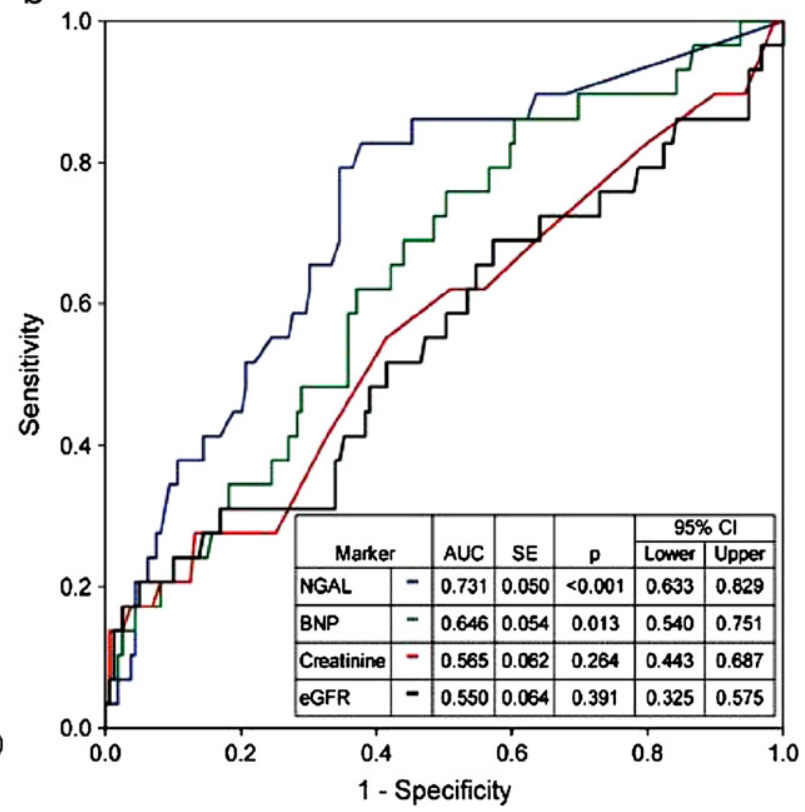

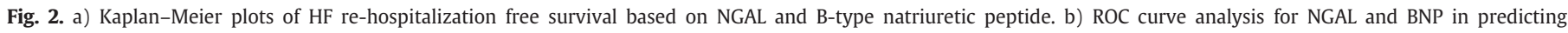
re-hospitalization or all-cause mortality in heart failure patients.

Data from Gallant Study Eur J Heart Fail [54]. 
Table 3

Complementary role of NGAL and BNP in patients with HF.

BNP

is a marker of neuro-hormonal activation as well as ventricular is a marker of kidney injury and in particular of renal tubular dysfunction and overload

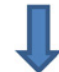
damage.

The combined measurement of blood BNP and NGAL levels seems to increase the prognostic accuracy in patients with HF: high levels of NGAL and BNP appear able to identify renal impairments as well as adverse outcome

markers of tubular damage: NGAL, N-acetyl-beta-D-glucosaminidase (NAG) and kidney injury molecule 1 (KIM-1) in patients with CHF. Tubular damage is also common in patients with CHF and mildly reduced GFR. NGAL, urinary KIM-1 and NAG show prognostic information additional to GFR [56]. Also the tubulo-interstitial injury might indicate renal damage, even in the presence of normal glomerular filtration. Damman et al. evaluated the relationship between the individual tubular damage markers, and found that all effects mortality and HF hospitalizations. Increased tubular markers were related to a poorer outcome in $\mathrm{HF}$ patients even when eGFR is normal. Urinary NGAL is a good index of tubular damage and significantly increased in patients with chronic HF and preserved renal function [57].

In the setting of HF, NGAL appears to be a marker of renal dysfunction and useful to identify patients at early stages of Cardio-Renal Syndrome (CRS). Alvelos et al. have investigated the performance of neutrophil gelatinase-associated lipocalin (NGAL) and cystatin $\mathrm{C}$ in the early detection of type 1 cardio-renal syndrome in patients with acute HF. They found a connection between NGAL and type 1 cardio-renal syndrome. This confirms the qualities of NGAL in the early recognition of these patients. A cutoff value of $170 \mathrm{ng} / \mathrm{L}$ is able to predict straight forward renal insufficiency in patients with preserved renal function at admission [58].

Serum levels of NGAL are augmented in patients with acute and chronic HF after myocardial infarction (MI). This value of NGAL is significantly correlated with clinical and neurohormonal deterioration. The increase of NGAL is a result of cardiomyocytes within failing myocardium, both in experimental and clinical HF. During acute or chronic heart failure the blood levels of interleukin-1beta and agonists for toll-like receptors 2 and 4 rise, components of the innate immune system. These molecules are potent inducers of NGAL/lipocalin-2 in isolated neonatal cardiomyocytes. Clinical and experimental HF support a role in innate immune responses in the pathogenesis of HF [59].

\section{Conclusions}

NP are peptides useful in the diagnosis of HF as they add new information compared to traditional diagnostic tools. NP measurement, combined to imaging methods, have been demonstrated to identify those subjects with higher systolic and diastolic dysfunctions, neuro-hormonal activation and hemodynamic impairment. Thus data confirm the prognostic role of NP in acute and chronic HF. NGAL is an emerging marker able to recognize at early stages patients with renal dysfunction. The impact of $\mathrm{RI}$ in HF setting is well recognized, so the identification of these patients before the onset of a renal dysfunction could help physicians in strategy treatment and risk prediction. In the future the combination of two laboratory markers, easily available in clinical practice, could lead to better patient classification of both patients with HF and cardio-renal syndrome as well as to tailor treatments.

\section{References}

[1] Cowie MR, Mosterd A, Wood DA, Deckers JW, Poole-Wilson PA, Sutton GC, et al. The epidemiology of heart failure. Eur Heart J 1997;18(2):208-25.

[2] Lloyd-Jones D, Adams R, Carnethon M, De Simone G, Ferguson TB, Flegal K, et al. Heart disease and stroke statistics-2009 update: a report from the American Heart Association Statistics Committee and Stroke Statistics Subcommittee. Circulation 2009;119:480-6.

[3] 2009 Focused Update: ACCF/AHA guidelines for the diagnosis and management of heart failure in adults: a report of the American college of cardiology foundation/America heart association task force on practice guidelines: developed in collaboration with the international society of heart and lung transplantation. Circulation 2009;119:1977-2016.

[4] Gheorghiade M, Abraham WT, Albert NM, Greenberg BH, O'Connor CM, She L, et al. OPTIMIZE-HF Investigators and Coordinators. Systolic blood pressure at admission, clinical characteristics, and outcomes in patients hospitalized with acute heart failure. JAMA 2006;296(18):2217-26.

[5] Felker GM, Pang PS, Adams KF, Cleland JG, Cotter G, Dickstein K, et al. Clinical trials of pharmacological therapies in acute heart failure syndromes: lessons learned and directions forward. Circ Heart Fail 2010;3(2):314-25.

[6] Metra M, Dei Cas L, Bristow MR. The pathophysiology of acute heart failure - it is a lot about fluid accumulation. Am Heart J 2008;155:1-5.

[7] Weintraub NL, Collins SP, Pang PS, Levy PD, Anderson AS, Arslanian-Engoren C, et al. Acute heart failure syndromes: emergency department presentation, treatment, and disposition: current approaches and future aims: a scientific statement from the American Heart Association. Circulation 2010;122(19):1975-96.

[8] Morrow DA, de Lemos JA. Benchmark for the assessment of novel cardiovascular biomarkers. Circulation 2007;115:949-52.

[9] Emdin M, Vittorini S, Passino C, Clerico A. Old and new biomarkers of heart failure. Eur J Heart Fail 2009;11:331-5.

[10] Braunwald E. Biomarkers in heart failure. N Engl J Med 2008;358:2148-59.

[11] Redfield MM, Rodeheffer RJ, Jacobsen SJ, Mahoney DW, Bailey KR, Burnett Jr JC. Plasma brain natriuretic peptide to detect preclinical ventricular systolic or diastolic dysfunction: a community-based study. Circulation 2004;109(25):3176-81.

[12] Dickstein K, Cohen-Solal A, Filippatos G, McMurray JJV, Ponikowski P, Poole-Wilson PA. ESC guidelines for the diagnosis and treatment of acute and chronic heart failure 2008: the Task Force for the Diagnosis and Treatment of Acute and Chronic Heart Failure 2008 of the European Society of Cardiology. Developed in collaboration with the Heart Failure Association of the ESC (HFA) and endorsed by the European Society of Intensive Care Medicine (ESICM). Eur Heart J 2008;29:2388e442.

[13] Mueller C, Scholer A, Laule-Kilian K, Martina B, Schindler C, Buser P, et al. Use of B-type natriuretic peptide in the evaluation and management of acute dyspnea. N Engl J Med 2004;350(7):647-54.

[14] Morrison LK, Harrison A, Krishnaswamy P, Kazanegra R, Clopton P, Maisel A. Utility of a rapid B-natriuretic peptide assay in differentiating congestive heart failure from lung disease in patients presenting with dyspnea. J Am Coll Cardiol 2002;39(2): 202-9.

[15] Maisel A, Hollander JE, Guss D, et al. Primary results of the rapid emergency department heart failure outpatient trial (REDHOT). A multicenter study of B-type natriuretic peptide levels, emergency department decision making, and outcomes in patients presenting with shortness of breath. J Am Coll Cardiol 2004;44: 1328-33.

[16] Luchner A, Möckel M, Spanuth E, Möcks J, Peetz D, Baum H, et al. N-terminal pro brain natriuretic peptide in the management of patients in the medical emergency department (PROMPT): correlation with disease severity, utilization of hospital resources, and prognosis in a large, prospective, randomized multicentre trial. Eur J Heart Fail 2012;14(3):259-67.

[17] Rutten JH, Steyerberg EW, Boomsma F, van Saase JL, Deckers JW, Hoogsteden HC, et al. N-terminal pro-brain natriuretic peptide testing in the emergency department: beneficial effects on hospitalization, costs, and outcome. Am Heart J 2008;156(1):71-7.

[18] Song J, Li P, Li H, Wang Q. The clinical significance of a urinary B-type natriuretic peptide assay for the diagnosis of heart failure. Clin Chim Acta 2011;412(17-18):1632-6.

[19] Silver MA, Maisel A, Yancy CW, McCullough PA, Burnett Jr JC, Francis GS, et al. A clinical approach for the diagnostic, prognostic, screening, treatment monitoring, and therapeutic roles of natriuretic peptides in cardiovascular diseases. Congest Heart Fail 2004;10(Suppl. 3):1-30.

[20] Iwanaga Y, Nishi I, Furuichi S, Noguchi T, Sase K, Kihara Y, et al. B-type natriuretic peptide strongly reflects diastolic wall stress in patients with chronic heart failure. J Am Coll Cardiol 2006;47:742-8.

[21] Fonarow GC, Peacock WF, Horwich TB, Phillips CO, Givertz MM, Lopatin M, et al. Usefulness of B-type natriuretic peptide and cardiac troponin levels to predict in-hospital mortality from ADHERE. Am J Cardiol Jan. 15 2008;101(2):231-7.

[22] Bettencourt P, Azevedo A, Pimenta J, Friões F, Ferreira S, Ferreira A. Nterminal-pro-brain natriuretic peptide predicts outcome after hospital discharge in heart failure patients. Circulation 2004;110:2168-74.

[23] Aspromonte N, Valle R, Peacock WF, Vanderheyden M, Maisel A. Inpatient monitoring and prognostic importance of B-type natriuretic peptide. Congest Heart Fail 2008;14:30-4.

[24] Richards AM, Doughty R, Nicholls MG, MacMahon S, Sharpe N, Murphy J, et al. Plasma N-terminal pro-brain natriuretic peptide and adrenomedullin: prognostic utility and prediction of benefit from carvedilol in chronic ischemic left ventricular dysfunction. J Am Coll Cardiol 2006;37:1781-7.

[25] Masson S, Latini R, Anand IS, Vago T, Angelici L, Barlera S, et al. Direct comparison of B-type natriuretic peptide (BNP) and amino-terminal proBNP in a large 
population of patients with chronic and symptomatic heart failure: the Valsartan Heart Failure (Val-HeFT) data. Clin Chem 2006;52:1528-38.

[26] Horwich TB, Hamilton MA, Fonarow GC. B-type natriuretic peptide levels in obese patients with advanced heart failure. J Am Coll Cardiol 2006;47:85-90.

[27] Noveanu M, Breidthardt T, Cayir S, Potocki M, Laule K, Mueller C. B-type natriuretic peptide-guided management and outcome in patients with obesity and dyspnearesults from the BASEL study. Am Heart J 2009;158(3):488-95.

[28] Daniels LB, Clopton P, Bhalla V, Krishnaswamy P, Nowak RM, McCord J, et al. How obesity affects the cut-points for B-type natriuretic peptide in the diagnosis of acute heart failure. Results from the Breathing Not Properly Multinational Study. Am Heart J 2006;151:999-1005.

[29] Redfield MM, Rodeheffer RJ, Jacobsen SJ, Mahoney DW, Bailey KR, Burnett JC. Plasma brain natriuretic peptide concentration: impact of age and gender. J Am Coll Cardiol 2002;40:976-82.

[30] Daniels LB, Bhalla V, Clopton P, Hollander JE, Guss D, McCullough PA, et al. B-type natriuretic peptide (BNP) levels and ethnic disparities in perceived severity of heart failure: results from the Rapid Emergency Department Heart Failure Outpatient Trial (REDHOT) multicenter study of BNP levels and emergency department decision making in patients presenting with shortness of breath. J Card Fail 2006;12:281-5.

[31] Balik M, Jabor A, Otahal M, Waldauf P, Pavlisova M. Impact of acute renal failure on the relationship between N-terminal pro-B-type natriuretic peptide and hemodynamic parameters. Blood Purif 2011;31:47-54.

[32] Cruz DN, Goh CY, Palazzuoli A, Slavin L, Calabrò A, Ronco C, et al. Laboratory parameters of cardiac and kidney dysfunction in cardio-renal syndrome. Heart Fail Rev 2011;16:545-51.

[33] Tigen K, Karaahmet T, Cevik C, Gurel E, Mutlu B, Basaran Y. Prognostic utility of anemia and pro-B-type natriuretic peptide in patients with nonischemic dilated cardiomyopathy and normal renal function. Am J Med Sci 2009;337:109-15.

[34] Zhou B, Yang J, Yang X, He Y, Zhao C, Xu S, et al. Usefulness of the Echocardiographic Multi-Parameter Score (EMPS) in evaluating left ventricular global heart function. Tex Heart Inst J 2011;38(1):27-34.

[35] Maisel AS, Koon J, Krishnaswamy P, Kazenegra R, Clopton P, Gardetto N, et al. Utility of B-natriuretic peptide as a rapid, point-of-care test for screening patients undergoing echocardiography to determine left ventricular dysfunction. Am Heart J 2001;141: 367-74.

[36] Dokainish H, Zoghbi WA, Ambriz E, Lakkis NM, Quinones MA, Nagueh SF. Comparative cost-effectiveness of B-type natriuretic peptide and echocardiography for predicting outcome in patients with congestive heart failure. Am J Cardiol Feb. 1 2006;97(3):400-3.

[37] Troughton RW, Richards AM. B-type natriuretic peptides and echocardiographic measures of cardiac structure and function. JACC Cardiovasc Imaging 2009;2: 216-25.

[38] Vinereanu D, Lim PO, Frenneaux MP, Fraser AG. Reduced myocardial velocities of left ventricular long-axis contraction identify both systolic and diastolic heart failure -a comparison with brain natriuretic peptide. Eur J Heart Fail 2005;7(4):512-9.

[39] Maeder Kaye DM. Heart failure with normal left ventricular ejection fraction. J Am Coll Cardiol 2009:53:905-18.

[40] Grewal J, McKelvie R, Lonn E, Tait P, Carlsson J, Gianni M, et al. BNP and NTproBNP predict echocardiographic severity of diastolic dysfunction. Eur J Heart Fail 2008; 10: 252-9.

[41] Tscope C, Kasner M, Westermann D, Gaub R, Poller WC, Schultheiss HP. The role of NT proBNP in the diagnostics of isolated diastolic dysfunction: correlation with echocardiographic and invasive measurements. Eur Heart J 2005;26:2277-84.

[42] Lubien E, DeMaria A, Krishnaswamy P, Clopton P, Koon J, Kazanegra R, et al. Utility of B-natriuretic peptide in detecting diastolic dysfunction: comparison with Doppler velocity recordings. Circulation 2002;105:595-601.

[43] Whalley GA, Wright SP, Pearl A, Gamble GD, Walsh HJ, Richards M, et al. Prognostic role of echocardiography and brain natriuretic peptide in symptomatic breathless patients in the community. Eur Heart J 2008;29(4):509-16.
[44] Bistola V, Parissis JT, Paraskevaidis I, Panou F, Nikolaou M, Ikonimidis I, et al. Prognostic value of tissue Doppler right ventricular systolic and diastolic dysfunction indexes combined with plasma B type natriuretic peptide in patients with advanced heart failure secondary to ischemic or idiopathic dilated cardiomyopathy. Am J Cardiol 2010;105:249-54.

[45] Bruder O, Jensen C, Jochims M, Farazandeh M, Barkhausen J, Schlosser T, et al Relation of B-type natriuretic peptide (BNP) and infarct size as assessed by contrast-enhanced MRI. Int J Cardiol 2010;144(1):53-8.

[46] Haeck JD, Verouden NJ, Kuijt WJ, Koch KT, Van Straalen JP, Fischer J, et al. Comparison of usefulness of N-terminal pro-brain natriuretic peptide as an independent predictor of cardiac function among admission cardiac serum biomarkers in patients with anterior wall versus nonanterior wall ST-segment elevation myocardial infarction undergoing primary percutaneous coronary intervention. Am J Cardiol 2010;105(8): 1065-9.

[47] Mayr A, Mair J, Schocke M, Klug G, Pedarnig K, Haubner BJ, et al. Predictive value of NT-pro BNP after acute myocardial infarction: relation with acute and chronic infarct size and myocardial function. Int J Cardiol 2011;147(1):118-23.

48] Krittayaphong R, Boonyasirinant T, Saiviroonporn P, Thanapiboonpol P, Nakyen S, Udompunturak S. Correlation between NT-pro BNP levels and left ventricular wall stress, sphericity index and extent of myocardial damage: a magnetic resonance imaging study. J Card Fail 2008;14(8):687-94.

[49] Nakae I, Matsuo S, Koh T, Mitsunami K, Horie M. Left ventricular systolic/diastolic function evaluated by quantitative ECG-gated SPECT: comparison with echocardiography and plasma BNP analysis. Ann Nucl Med 2005;19(6):447-54.

[50] Aktas MK, Allen D, Jaber WA, Chuang HH, Taylor DO, Yamani MH. Relation of brain natriuretic peptide level to extent of left ventricular scarring in patients with chronic heart failure secondary to ischemic cardiomyopathy. Am J Cardiol Jan. 15 2009;103(2):243-5.

[51] Hall IE, Coca SG, Perazella MA, Eko UU, Luciano RL, Peter PR, et al. Risk of poor outcomes with novel and traditional biomarkers at clinical AKI diagnosis. Clin J Am Soc Nephrol 2011;6(12):2740-9.

52] Aghel A, Shrestha K, Mullens W, Borowski A, Tang WH. Serum neutrophil gelatinase-associated lipocalin (NGAL) in predicting worsening renal function in acute decompensated heart failure. J Card Fail 2010;16(1):49-54.

[53] Alvelos M, Lourenço P, Dias C, Amorim M, Rema J, Leite AB, et al. Prognostic value of neutrophil gelatinase-associated lipocalin in acute heart failure. Int J Cardiol 2011 Aug 26 [Electronic publication ahead of print].

[54] Maisel AS, Mueller C, Fitzgerald R, Brikhan R, Hiestand BC, Iqbal N, et al. Prognostic utility of plasma neutrophil gelatinase-associated lipocalin in patients with acute heart failure: the NGAL EvaLuation Along with B-type NaTriuretic Peptide in acutely decompensated heart failure (GALLANT) trial. Eur J Heart Fail 2011;13(8): 846-51.

[55] Poniatowski B, Malyszko J, Bachorzewska-Gajewska H, Malyszko JS, Dobrzycki S. Serum neutrophil gelatinase-associated lipocalin as a marker of renal function in patients with chronic heart failure and coronary artery disease. Kidney Blood Press Res 2009;32(2):77-80.

[56] Damman K, Van Veldhuisen DJ, Navis G, Vaidya VS, Smilde TD, Westenbrink BD, et al. Tubular damage in chronic systolic heart failure is associated with reduced survival independent of glomerular filtration rate. Heart 2010;96(16):1297-302.

[57] Damman K, Masson S, Hillege HL, Maggioni AP, Voors AA, Opasich C, et al. Clinica outcome of renal tubular damage in chronic heart failure. Eur Heart J 2011;32(21): 2705-12.

[58] Alvelos M, Pimentel R, Pinho E, Gomes A, Lourenço P, Teles MJ, et al. Neutrophil gelatinase-associated lipocalin in the diagnosis of type 1 cardio-renal syndrome in the general ward. Clin J Am Soc Nephrol 2011;6(3):476-81.

[59] Yndestad A, Landrø L, Ueland T, Dahl CP, Flo TH, Vinge LE, et al. Increased systemic and myocardial expression of neutrophil gelatinase-associated lipocalin in clinical and experimental heart failure. Eur Heart J 2009;30(10):1229-36. 